\title{
Esophageal Cancer with Solitary Renal Metastasis Treated with Multidisciplinary Therapy: A Case Report and Mini Review of the Literature
}

\author{
Kyoung Sik Nam, Kyoungwon Jung, Moo In Park, Seun Ja Park, Won Moon, Sung Eun Kim, Jae Hyun Kim \\ Department of Internal Medicine, Kosin University College of Medicine, Busan, Korea
}

\begin{abstract}
Solitary renal metastasis of esophageal cancer is rarely encountered. Herein, we report the case of a 47-year-old man who developed a solitary renal metastasis after concurrent chemoradiotherapy followed by esophagectomy with esophagogastrostomy for esophageal squamous cell carcinoma, and treatment with nephrectomy and subsequent chemotherapy. Histopathological evaluation after operation revealed that the kidney mass was a metastatic lesion from esophageal cancer. He completed 15 cycles of palliative chemotherapy after nephrectomy and remained cancer-free for 36 months. Although lymph node metastasis occurred during regular follow-up, no evidence of lymph node metastasis was found on the imaging study after 9 cycles of chemotherapy with radiotherapy. (Korean J Helicobacter Up Gastrointest Res 2017;17:39-44)
\end{abstract}

Key Words: Esophageal cancer; Neoplasm metastasis; Survival; Multidisciplinary therapy

\section{INTRODUCTION}

Esophageal cancer is a malignant disease with aggressive behavior which is characterized by a high recurrence rate, advanced stage at diagnosis, and poor 5-year overall survival that rarely exceeds $30 \%{ }^{1,2}$ There are several treatment options for esophageal cancer, including surgical resection, preoperative or definitive chemoradiotherapy, or systemic chemotherapy. ${ }^{3}$ Although $50 \%$ to $70 \%$ of patients can be treated surgically with $\mathrm{Cu}^{-}$ rative intent, half of these patients suffer from local recurrence or distant metastasis after complete resection. ${ }^{4}$ The most common sites of metastasis are the liver, lungs, bones, and adrenal glands through the hematogenous route. ${ }^{4,5}$ However, the development of a solitary renal metastasis of esophageal cancer has rarely been reported. Herein, we report a case of solitary renal metastasis after esophagectomy of advanced esophageal cancer treated by multimodality.

Received: December 6, 2016 Revised: January 3, 2016 Accepted: January 4, 2017

Corresponding author: Kyoungwon Jung

Department of Internal Medicine, Kosin University College of Medicine, 262 Gamcheon-ro, Seo-gu, Busan 49267, Korea

Tel: +82-51-990-6103, Fax: +82-51-990-5055, E-mail: forjkw@gmail.com

\section{CASE REPORT}

A 47-year-old man visited the outpatient clinic for an evaluation of dysphagia for about 2 months. On the esophagogastroduodenoscopy, an ulceroinfiltrative mass was found in the mid-esophagus, which suggested advanced esophageal cancer, Borrmann type 3. Histopathological examination determined the mass was moderately differentiated squamous cell carcinoma (Fig. 1). CT scan of the chest showed diffuse wall thickening of the mid-esophagus and enlargement of the paratracheal lymph node, and these lesions were found to be hypermetabolic lesions in fluorodeoxyglucose (FDG) PET-CT scan. There was no distant metastasis. The patient was diagnosed as an advanced esophageal cancer without distant metastasis which was clinical stage IIB or IIIA.

The patient underwent two cycles of chemotherapy with 5 -fluorouracil $\left(5\right.$-FU; $\left.1,000 \mathrm{mg} / \mathrm{m}^{2}\right)$ on day 1 to 4 and cisplatin $\left(75 \mathrm{mg} / \mathrm{m}^{2}\right)$ on day 1 . Concurrently, he received radiotherapy with a total dose of 5,040 cGy divided by 28 fractions. After chemoradiotherapy, he underwent esophagectomy and esophagogastrostomy (IvorLewis operation) of curative intent. After the surgery, he suffered from benign anastomotic stricture. He underwent

Copyright $\odot 2017$ Korean College of Helicobacter and Upper Gastrointestinal Research

(a) The Korean Journal of Helicobacter and Upper Gastrointestinal Research is an Open-Access Journal. All articles are distributed under the terms of the Creative Commons Attribution Non-Commercia License (http://creativecommons.org/licenses/by-nc/4.0) which permits unrestricted non-commercial use, distribution, and reproduction in any medium, provided the original work is properly cited. 

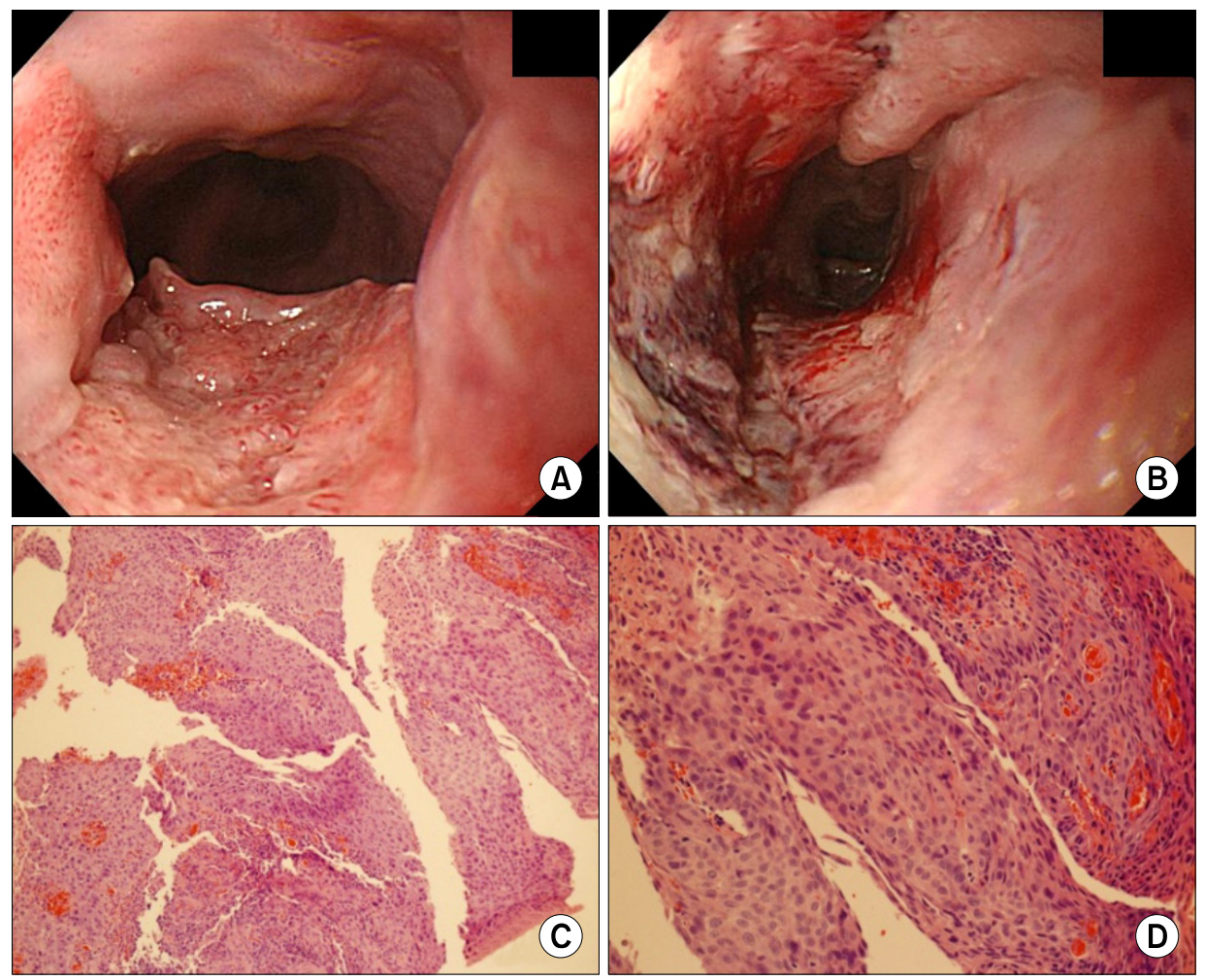

Fig. 1. (A, B) Endoscopic and histopathological findings of primary esophageal cancer. At the 29 to $35 \mathrm{~cm}$ from the upper incisor, about $6 \mathrm{~cm}$ in size, circumscribed mass with overlying friable depressed ulceration is found in the upper endoscopy. (C, D) The histological finding of biopsy specimens shows moderately differentiated squamous cell carcinoma (H\&E; C: $\times 100$, D: $\times 200$ ).

two sessions of balloon dilatation and temporary metal stent placement. Sixteen months later, a 5-cm-sized left renal mass was identified on regular surveillance CT and PET-CT scans (Fig. 2). For the best option of treatment for left renal mass, a multidisciplinary team meeting was held. After discussion, because of the difficulty of differentiate between renal cell carcinoma and metastasis, left nephrectomy was performed. On histopathological examination, the renal mass was revealed to be a metastatic lesion from esophageal cancer that was similar to the histological findings of the previously resected esophageal squamous cell carcinoma (Fig. 3). There was no recurrence on scheduled follow-up examinations during palliative chemotherapy with 5-FU and cisplatin after nephrectomy. Complete remission was achieved after 15 cycles of chemotherapy, the treatment was discontinued due to drug toxicity. Three years after the last chemotherapy, a lymph node enlargement appeared at the subcarinal area on a chest $\mathrm{CT}$, which also demonstrated high uptake of FDG in PET-CT scan. As a result of consultation with clinicians of department of oncology and radiation oncology, docetaxel monotherapy and additional radiotherapy was performed. After 9 cycles of chemotherapy, the size of the lymph node decreased and became almost invisible on the CT scan, and FDG uptake was no longer observed on PET-CT can. He is currently undergoing chemotherapy without any other recurrence. The flow of the treatment was summarized in Fig. 4.

\section{DISCUSSION}

The prevalence of esophageal cancer is highest in east Asia, eastern and southern Africa, and some countries of Europe. ${ }^{6}$ Esophageal squamous cell carcinoma is the eighth most common cancer and the sixth leading cause of death in 2012. ${ }^{2}$ Most patients with esophageal cancer die of recurrence or metastasis, with the 5-year overall survival rate ranging from $15 \%$ to $25 \% .^{1}$ Once disseminated, metastases from esophageal cancer occur in various organs, including the liver, lungs, bones, and adrenal glands. ${ }^{4,5}$

Metastatic renal tumors are rare and are mainly detected at autopsy. Bracken et al. ${ }^{7}$ reviewed 11,328 autopsies and identified $816(7.2 \%)$ cases of metastatic tumor in 

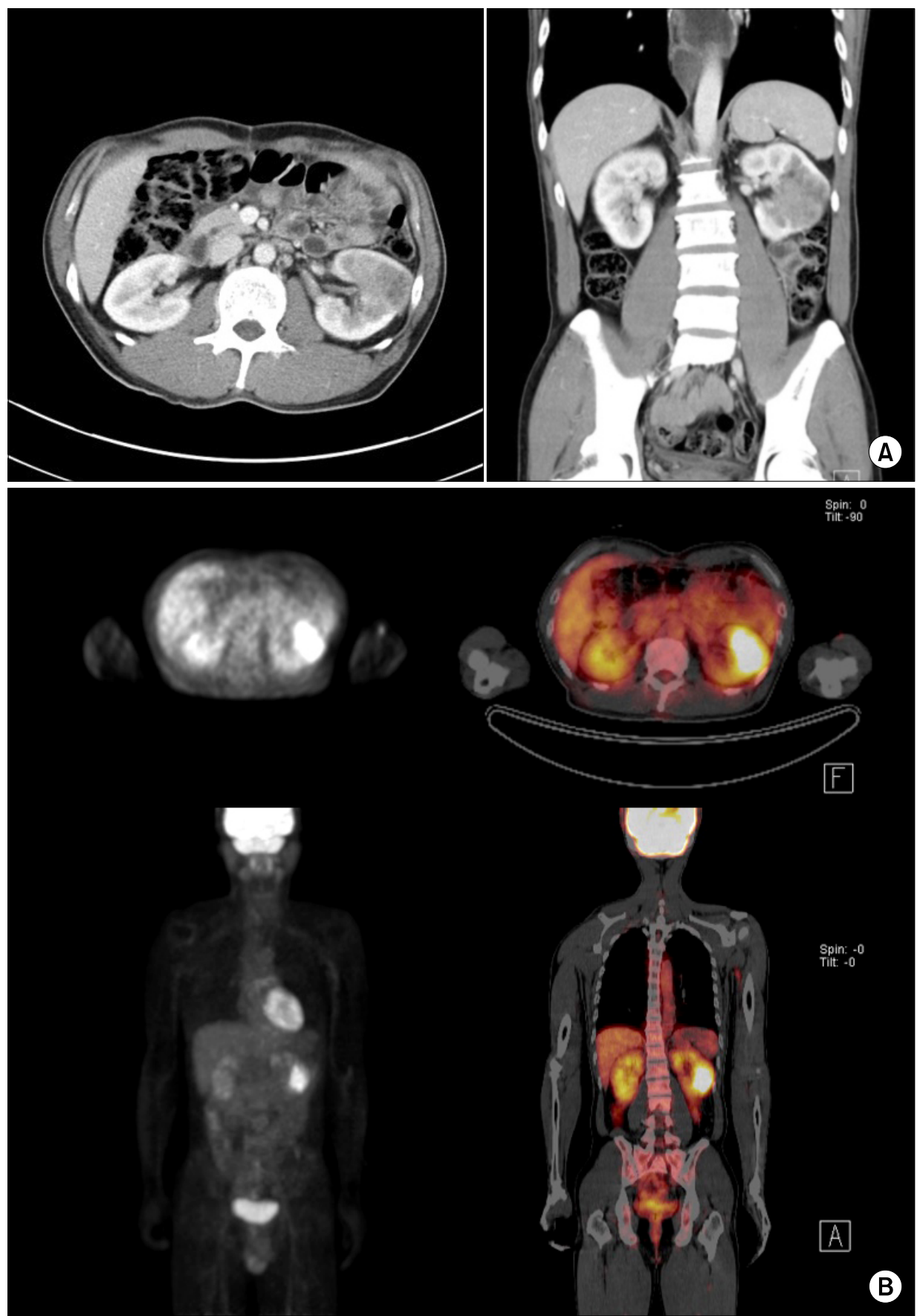

Fig. 2. Abdominal CT and a whole body fluorodeoxyglucose (FDG)-PET scans of the patient performed at 17 months after esophagectomy. (A) An approximate $4.7 \times 3.6-\mathrm{cm}$-sized illdefined low density mass is detected on the mid to lower pole of the left kidney. (B) Single mass with high FDG uptake is found on the lateral cortex area of the left kidney. The mass correlates with the mass detected on the abdominal CT scan.

the kidney. The sites of primary tumors include the lung, breast, skin, genitourinary, gastrointestinal, and gynecologic tracts in order of decreasing frequency. Because renal metastasis occurred through a hematogenous route, renal metastases usually present with multiple and bilateral lesions of less than $3 \mathrm{~cm}$ in size, which are widely spaced throughout the renal parenchyma. Previous report showed that only $10 \%$ of metastatic renal tumors are more than $3 \mathrm{~cm}$ in size at the diagosis. In addition, metastatic lesions tend to be less exophytic and wedgeshaped compared to the primary tumor of the kidney because of their subcapsular location. ${ }^{8}$ In the present case, renal metastasis appeared as a solitary, wedge-shaped mass located in the subcapsular area. 

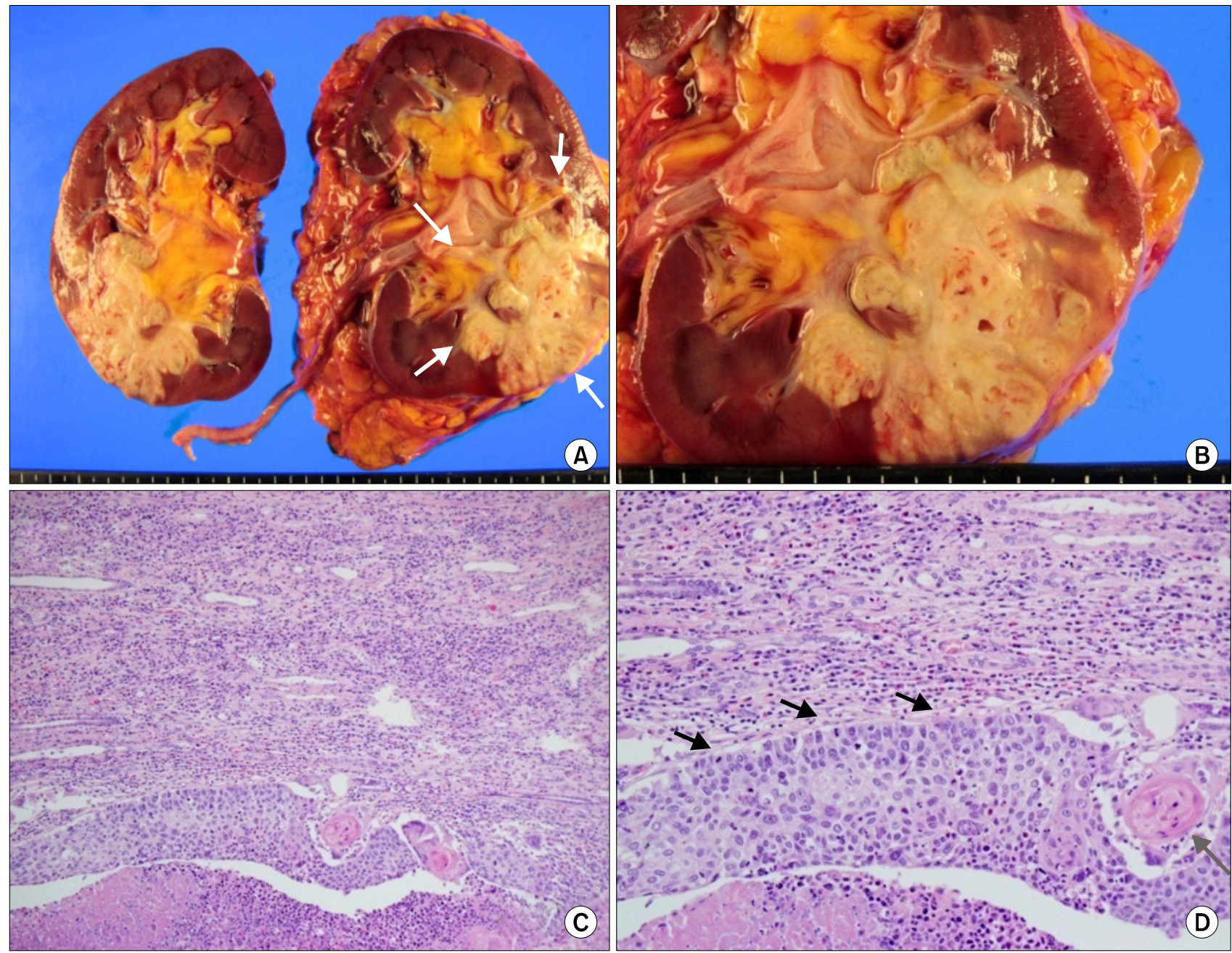

Fig. 3. (A, B) Gross and microscopic findings of resected kidney mass. Subcapsular mass is identified at the mid to lower pole of the left kidney. The tumor is whitish in color with an infiltrating margin, and $5 \mathrm{~cm}$ at its greatest dimension (A: white color arrows). (C, D) Microscopic examination of the resected renal mass shows a metastatic squamous cell carcinoma with nuclear irregularity (black color arrows) and compact laminated keratin (keratin pearls) (grey color arrow), which is similar to the histological findings of the previously resected esophageal squamous carcinoma (H\&E; C: $\times 100, \mathrm{D}: \times 200)$.

Most renal metastases are asymptomatic despite extensive growth, and therefore they are generally detected late. In one study, only $33 \%$ of patients had microscopic hematuria and $15 \%$ developed gross hematuria. ${ }^{10}$ Therefore, the diagnosis of renal metastases is very difficult, particularly in patients with esophageal cancer, and is often established accidentally on surveillance exams. Although previous study based on autopsy findings showed that $13 \%$ of esophageal cancer had metastatic lesions in the kidney, ${ }^{11}$ such cases are rarely encountered in the clinical practice because they are asymptomatic. The present case in addition to the other 11 previously re- ported cases of esophageal cancer with renal metastasis and their treatment are briefly summarized in Table 1. ${ }^{8,12-20}$ Some cases had undergone surgical treatment because the differentiation between metastasis and primary renal tumor was difficult. Others were treated with surgical resection followed by chemotherapy and showed longer survival than those received surgical treatment alone, although this difference was not statically significant.

In this case, the patient achieved a partial response after concurrent neoadjuvant chemotherapy with irradiation. About 17 months after the curative esophagectomy, recurrence occurred with a solitary renal metastasis. 


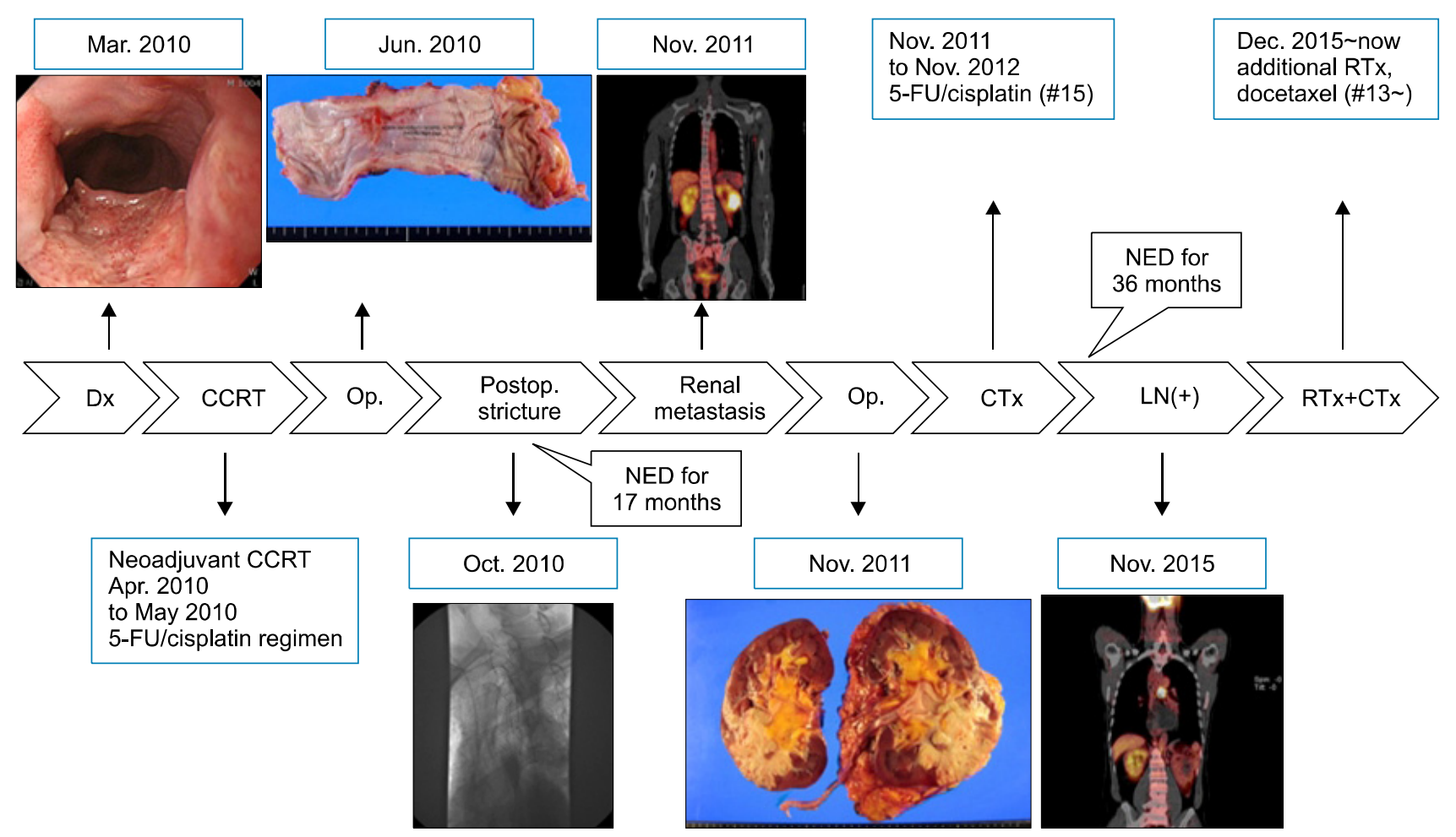

Fig. 4. Treatment course of this patient. 5-FU, 5-fluorouracil; RTx, radiotherapy; Dx, diagnosis; CCRT, concurrent chemoradiotherapy; Op., operation; Postop., postoperative; CTx, chemotherapy; LN, lymph node; CTx, chemotherapy; NED, no evidence of disease.

Table 1. Reported Cases of Esophageal Squamous Cell Carcinoma with Renal Metastasis

\begin{tabular}{|c|c|c|c|c|c|c|}
\hline Case & Year & $\begin{array}{l}\text { Age (yr)/ } \\
\text { gender }\end{array}$ & $\begin{array}{l}\text { Tumor } \\
\text { type }\end{array}$ & $\begin{array}{c}\text { Interval between } \\
\text { metastasis from } \\
\text { primary tumor (mo) }\end{array}$ & $\begin{array}{l}\text { Survival time after } \\
\text { renal metastasis } \\
(\mathrm{mo})\end{array}$ & Treatment of renal metastasis \\
\hline Kitami et al. ${ }^{12}$ & 1987 & 61/male & SCC & 11 & 2 & Left nephrectomy \\
\hline Nagai et al. ${ }^{13}$ & 1989 & $50 /$ male & SCC & 24 & 4 & Radiotherapy and right nephrectomy \\
\hline Shimizu et al. ${ }^{14}$ & 1990 & $62 /$ male & SCC & 5 & NA & Left nephrectomy \\
\hline Miyoshi et al. ${ }^{15}$ & 1997 & 57/male & SCC & 2 & $>24$ & Right nephrectomy \\
\hline (two cases) & & $57 /$ male & SCC & 12 & 2 & Right nephrectomy \\
\hline Matsushita et al. ${ }^{16}$ & 1998 & 74/male & SCC & 13 & 3 & Right partial nephrectomy \\
\hline Lim et al. ${ }^{8}$ & 2004 & $61 /$ male & SCC & 24 & NA & Right radical nephrectomy and chemotherapy \\
\hline $\mathrm{Ku}$ et al. ${ }^{17}$ & 2005 & $65 /$ male & SCC & 21 & $>6$ & Right nephrectomy and chemotherapy \\
\hline Lai et al. ${ }^{18}$ & 2012 & $46 /$ male & SCC & 24 & 24 & Chemotherapy \\
\hline Sun et al. ${ }^{19}$ & 2014 & $64 /$ male & SCC & 9 & 3 & Right nephrectomy \\
\hline Chang et al. ${ }^{20}$ & 2016 & $53 /$ male & SCC & 31 & 2 & Left nephroureterectomy \\
\hline This present case & 2016 & 47/male & SCC & 17 & 47 & Left radical nephrectomy and chemotherapy \\
\hline
\end{tabular}

SCC, squamous cell carcinoma; NA, not available.

Regarding the treatment of renal metastasis, it is often difficult for clinicians to decide whether to proceed a surgery or palliative chemotherapy because no definitive diagnosis can be made based on the findings of imaging studies. Radical nephrectomy could be justified in limited situations, such as refractory hematuria with anemia.
Moreover, the role of chemotherapy after radical nephrectomy with clear resection margins has not been established. Multidisciplinary team approach is crucial in making a decision for the treatment that can lead to optimal outcomes and prolonged survival. In our case, we performed chemotherapy for one year and discontinued 
treatment when no measurable lesion was observed on periodic CT scans. Finally, he completed 15 cycles of palliative chemotherapy after nephrectomy and remained cancer-free for 36 months. Lymph node metastasis occurred during regular follow-up, and complete remission was achieved after 9 cycles of chemotherapy and radiotherapy. The treatment based on multidisciplinary team approach that incorporates clinicians in the departments of thoracic surgery, oncology, radiation oncology, urology, and gastroenterology contributed to longer survival of patient. Our case confirmed that comprehensive assessment is beneficial in the diagnosis and treatment of the patients with esophageal cancer.

In summary, we reported a case of advanced esophageal cancer with solitary renal metastasis treated with multidisciplinary team approach which lead to long-term survival. Although the prognosis of metastatic esophageal cancer is poor, more aggressive treatment including surgery can be beneficial.

\section{REFERENCES}

1. Hamai Y, Hihara J, Emi M, et al. Results of neoadjuvant chemoradiotherapy with docetaxel and 5-fluorouracil followed by esophagectomy to treat locally advanced esophageal cancer. Ann Thorac Surg 2015;99:1887-1893.

2. Gupta B, Kumar N. Worldwide incidence, mortality and time trends for cancer of the oesophagus. Eur J Cancer Prev 2016. doi: 10.1097/CEJ.0000000000000249. [Epub ahead of print]

3. Le Bras GF, Farooq MH, Falk GW, Andl CD. Esophageal cancer: The latest on chemoprevention and state of the art therapies. Pharmacol Res 2016;113:236-244.

4. Mariette C, Balon JM, Piessen G, Fabre S, Van Seuningen I, Triboulet JP. Pattern of recurrence following complete resection of esophageal carcinoma and factors predictive of recurrent disease. Cancer 2003;97:1616-1623.

5. Shiozaki H, Sudo K, Xiao L, et al. Distribution and timing of distant metastasis after local therapy in a large cohort of patients with esophageal and esophagogastric junction cancer.
Oncology 2014;86:336-339.

6. Pickens A, Orringer MB. Geographical distribution and racial disparity in esophageal cancer. Ann Thorac Surg 2003;76: S1367-S1369.

7. Bracken RB, Chica G, Johnson DE, Luna M. Secondary renal neoplasms: an autopsy study. South Med J 1979;72:806-807.

8. Lim DH, Im YH, Ji SH, et al. Esophageal squamous cell carcinoma recurring as a solitary renal mass. Cancer Res Treat 2004;36: 271-274.

9. Hietala SO, Wahlqvist L. Metastatic tumors to the kidney. A postmortem, radiologic and clinical investigation. Acta Radiol Diagn (Stockh) 1982;23:585-591.

10. Choyke PL, White EM, Zeman RK, Jaffe MH, Clark LR. Renal metastases: clinicopathologic and radiologic correlation. Radiology 1987;162:359-363.

11. Anderson LL, Lad TE. Autopsy findings in squamous-cell carcinoma of the esophagus. Cancer 1982;50:1587-1590.

12. Kitami K, Masuda M, Chiba K, Kumagai H. Metastatic renal tumor originating from esophageal carcinoma: a case report. Hinyokika Kiyo 1987;33:1221-1225.

13. Nagai T, Takashi M, Sakata T, Sahashi M, Simoji T, Miyake K. A case of esophageal cancer metastatic to the kidney presenting as renal pelvic cancer. Hinyokika Kiyo 1989;35:1565-1568.

14. Shimizu H, Koyama Y, Ozawa I, et al. An esophageal cancer with a renal metastasis that was detected and resected as the only focus of recurrence. Gan No Rinsho 1990;36:2047-2052.

15. Miyoshi Y, Asakura T, Matsuzaki J, Fukuda M, Satomi Y. Metastatic renal tumor originating from esophageal cancer: report of 2 cases. Hinyokika Kiyo 1997;43:347-350.

16. Matsushita $\mathrm{Y}$, Katoh T, Isurugi K, et al. Metastatic renal tumor originating from esophageal carcinoma: a case report. Hinyokika Kiyo 1998;44:591-594.

17. Ku JH, Park HK, Lee E, Heo DS, Kim HH. Solitary squamous cell carcinoma in the kidney after metachronous development of esophageal and lung cancer. Tumori 2005;91:93-95.

18. Lai YC, Lai JI, Lin PC, Wang WS, Chen YC. Esophageal squamous cell carcinoma with solitary renal metastasis-a case report. J Gastroenterol Hepatol Res 2012;1:230-232.

19. Sun Y, Yu X, Zhang Y. Renal metastasis after esophagectomy of esophageal squamous cell carcinoma: a case report and literature review. World J Surg Oncol 2014;12:165.

20. Chang KP, Huang CP, Chang H. Solitary renal metastasis of esophageal squamous cell carcinoma mimicking primary renal neoplasm-a case report and literature review. Biomedicine (Taipei) 2016;6:6. 